\title{
New TD-20 Diesel Crawler Tractor
}

International Harvester Company of Canada, Limited, recently introduced a new $134 \mathrm{hp}$ Diesel crawler tractor designated as the International TD-20.

The TD-20 is said to offer a major advance in crawler tractor design in its power class with a six-speed full reverse transmission. With a single lever, the company points out, an operator can shift the transmission through six speed ranges. A separate lever operates the forward-reverse "shuttle bar" control which provides six speed ranges forward and six in reverse.

Because of this unique design, TD-20 operators can make full use of the high reverse speeds available because of the planned shift pattern. When the directional "shuttle bar" shift lever is moved the tractor travels either forward or reverse in any pre-selected speed range.

Full performance data are available from International Harvester Company of Canada, Limited, 208 Hillyard Street, Hamilton, Ontario.

\section{S.A.F. Launches Study of Educatron}

A nation-wide study of education in forestry and related fields of natural resources management will be started in June by the Society of American Foresters, according to an announcement by George A. Garratt, Society president. The project has been made possible by a grant from the Old Dominion Foundation, Inc., of New York City.

The inquiry will try to find solutions for certain problems involving the adequacy of existing schools, curriculums, faculties, and student recruitment. The relation of the professional schools to the colleges and universities that give subprofessional and specialized courses in the subjects having to do with the management of renewable natural resources will be examined. Among other things, an attempt will be made to answer the question "how good?" as well as "how much?"

A report of the findings will be published by the Society as a book. It should be available early in 1960 .

\section{Barnes Named Land Use Adviser}

A professional forester, A. S. L. Barnes of Toronto, has been named forestry and land use adviser to the West Indies. Mr. Barnes, who is assistant director of the Conservation Branch, Department of Planning and Development, has been granted a year's leave of absence from his position to act as adviser to the newly-created federated government of the West Indies. His principal function will be to establish a forestry and land use department for the island federation. At present, the West Indies has no such department on a federation level. 